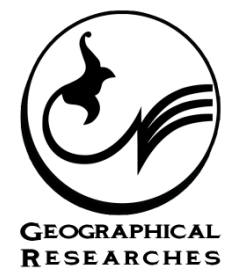

\title{
Environmental Sustainability Components and Architecture Design of Iranian Educational Buildings
}

\section{ART ICLE INFO}

\section{Article Type}

Original Research

\section{Authors}

Bareshadat N. ${ }^{1} M A$,

Shoaei HR. ${ }^{2} P h D$

Rezvani AR. ${ }^{* 1} P h D$
How to cite this article Bareshadat N, Shoaei HR, Rezvani AR. Environmental Sustainability Components and Architecture Design of Iranian Educational Buildings. Geographical Researches. 2019;34(4):559-565

\section{A B S T R A C T}

Aims \& Backgrounds Today, environmental developments, climate change, and energy problems are major challenges in the world. Although Iran has been at the beginning of sustainable development regarding the buildings sustainability evaluation systems and has developed general guidelines and standards in this area, no effective action has been taken about schools. The present study aim is to determine priorities and sustainability indicators of designing sustainable educational spaces in Iran. Methodology This study is descriptive-analytical in nature and descriptive applied-development in terms of purpose. The method of data collection is library-based and questionnaires are completed by experts. Analytic Hierarchy Process (AHP) is used to determine the importance and weighting of components and indicators.

Findings Based on the hierarchical analysis of the components and indicators obtained from previous research, three components of energy, water and site design, as well as three indicators of water recycling, using renewable energy and optimizing water use for landscaping and irrigation were ranked as first to third.

Conclusion The tables and analytical charts showed that the priority and the rating of the effective factors on environmental sustainability in Iranian educational spaces include: energy, water, site design, indoor quality, materials, regional priority and design innovation. Among indicators, water recycling, renewable energy use and optimization of water use for landscaping and irrigation are ranked first to third.

Keywords Sustainability; Learning Environments; Evaluation System; Hierarchical Analysis
${ }^{1}$ Department of Architecture, Faculty of Art \& Architecture, Islamic Azad University, Mashhad, Iran ${ }^{2}$ Department of Architecture, Faculty of Engineering, Islamic Azad University, Shahrud, Iran

\section{*Correspondence}

Address: Department of Architecture, Faculty of Art \& Architecture, Islamic Azad University, Professor Yousefi Boulevard, Mashhad, Iran Phone: +98 (51) 36627510

Fax: +98 (51) 36641262 rezvanialireza@yahoo.com

\section{Article History}

Received: September 6, 2019

Accepted: November 14, 2019

ePublished: December 11, 2019

\section{I T A T I O N L I N K S}

[Alyami \& Rezgui;2012] Sustainable building assessment tool development approach; [Bahreini \& Maknoon;2001] Sustainable urban development from thought to Action; [Bareshadat, et al; 2019] Explaining the components and Indices of environmental sustainability in Iran's educational spaces, with an emphasis on green educational building evaluation systems; [Beheshty, et al; 2014] A sociological study of the impact of attitudes on energy consumption; [Bernardi, et al; 2017] An analysis of the most adopted rating systems for assessing the environmental impact of buildings; [Keung; 2016] Green building- building planning and massing; [LEED 2009 ;2016] LEED for schools-new construction v2009; [Lee; 2012] Benchmarking energy use of building environmental assessment schemes; [Mahdavi Nejad, et al; 2014] Dilemma of green and pseudo green architecture based on LEED norms in case of developing countries; [Majrohi Sardorood, et al; 2017] Evaluation of green building rating criteria in world standards and proposed standards for Iranian standard formulation; [Meybodi; 2015] Proposing a model of green schools assessment in Iran using fuzzy multi-criteria decision making methods; [Meybodi, et al; 2016] Developing standard criteria for geen schools in Iran; [Mohamadjani \& Yazdanian; 2014] Analysis of the situation of water crisis in the country and its management requirements; [OECD ;2001] The DAC guidelines, strategies for sustainable development; [Ramli, et al; 2012] A comparative study of green school guidelines; [Sadeghi, et al; 2017] The impact of renewable energy on economic growth and environmental quality in Iran 
يايدارى ساختمان ارايه كَرديده است. ليكن در ايران عليرغم اهميت

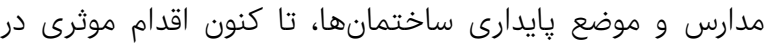
خصوص تدوين سيستم ارزيابى مرتبط صورت نيذيرفته است و اينا ماين

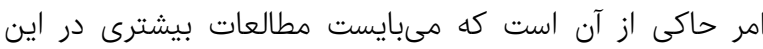
خصوص صورت پيذيرد.

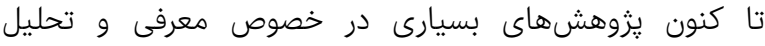
سيستمهاى ارزيابى فضاهاى آموزشى سبز در نشريات معتبر جهانى دروى دهري

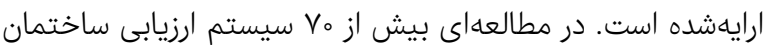

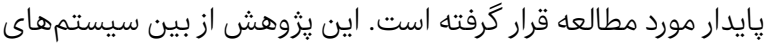

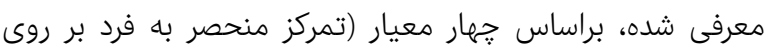

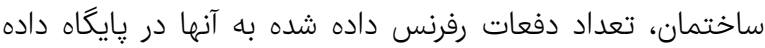
Scopus Elsevier يروزه معتبر و توسعه يكيارجه مناطق (در يك برنامه حداقل 0 ساله)،

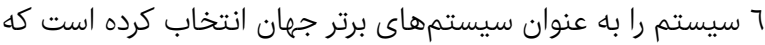
عبارتند از: (LEED) ايالات متحده (1991)؛ (BREEAM) انكُلستان

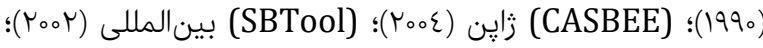

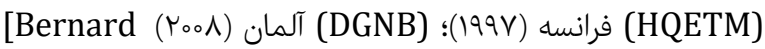
[et al, 2017. نتايج حاصل از يزوهشى ديخر شامل \& سيستم

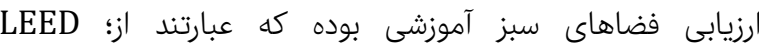
ايالاتمتحده، BREEAM انكلستان، Green Star استراليا،

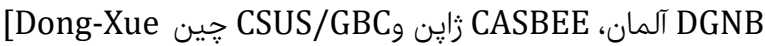

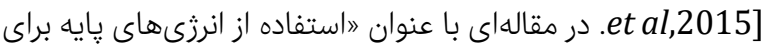
طراحى طرحهاى ارزيابى محيطزيسته به مقايسه ينج استاندارد

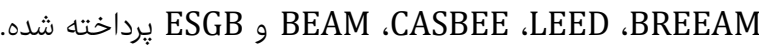
نتايج مقايسه نشان داد كه تمام ينج طرح براساس عملكرد نسبى

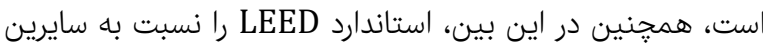

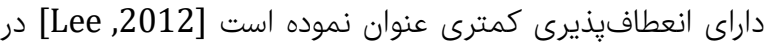
تحقيقى كه بر روى مهمترين روشهاى ارزيابى محيطى در سطح

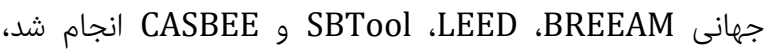
مشخص گرديد كه روشهاى موجود نمىتوانند به دلايلى در همه

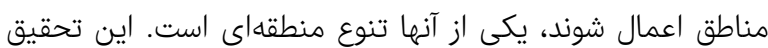

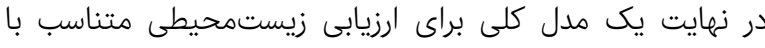

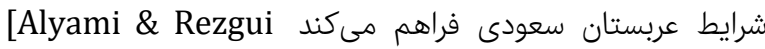

در سال rاor يك مطالعه مقايسهاى در مورد دستورالعملهاى ايجاد

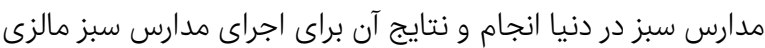
مورد بررسى قرار گرفت. نتايج حاكى از آن بود كه بايد اطلاعات و

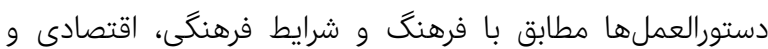

اجتماعى خود اصلاح شود [Ramli et al, 2012].

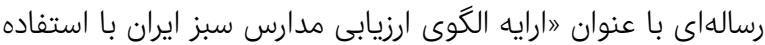

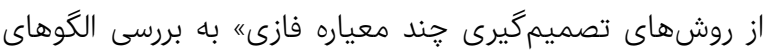

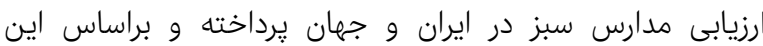

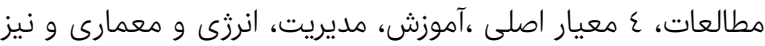

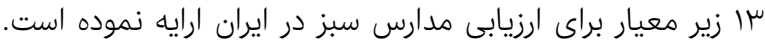

\section{مؤلفهها و شاخصهاى بايدارى محيطى در طراحى معمارى ساختمانهاى آموزشى ايران}

\author{
MA نكين بارشادت \\ كروه معمارى، دانشكده هنر و معمارى، دانشگاه آزاد اسلامى، مشهد، ايران \\ Pميدرضا شعاعى PhD \\ كَروه معمارى، دانشكده فنى مهندسى، دانشگاه آزاد اسلامى، شاهرود، ايران \\ عليرضا رضوانى PhD \\ كَروه معمارى، دانشكده هنر و معمارى، دانشكاه آزاد اسلامى، مشهد، ايران
}

جكيده

اهداف و زمينهها: امروزه تحولات زيستمحيطى، تغييرات آب و هوايى و

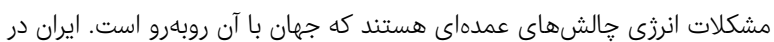

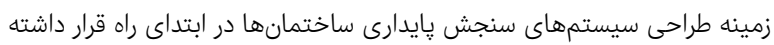

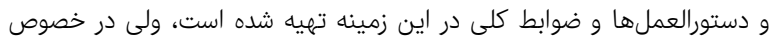

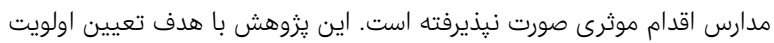

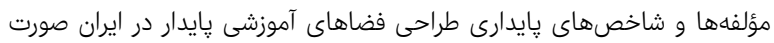

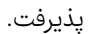

روششناسى: در اين يزوهش توصيفى- تحليلى، دادهها بهصورت كتابخانهاى و

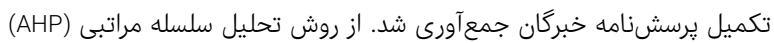

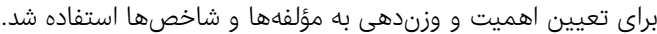

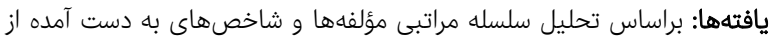
تحقيقات يِيشين، سه مؤلفه انرزى، آب و طراحى سايت و نيز سه شاخص بإئ بازيافت

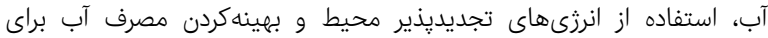

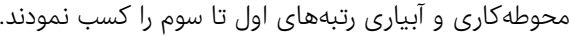

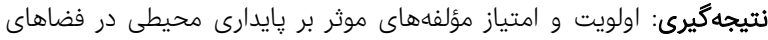

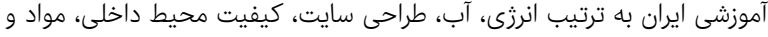

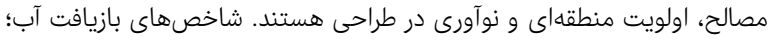

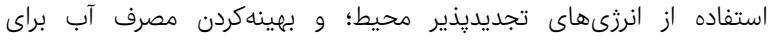
محوطهكارى و آبيارى؛ در رتبههاى اول تا سوم قرار مى تئيرند.

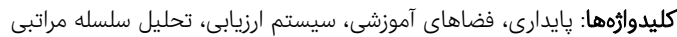

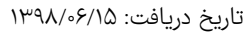

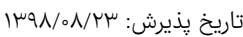

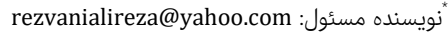

يايدارى به منظور توصيف جهانى كه در آن نظامهاى انسانى و

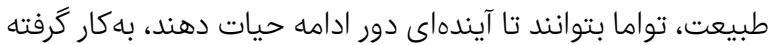

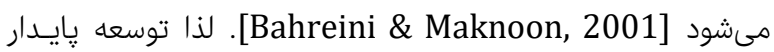

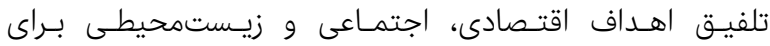

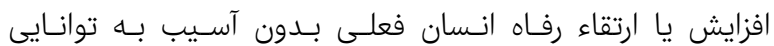

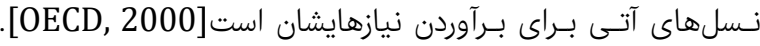

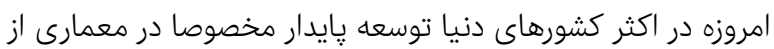

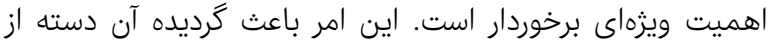

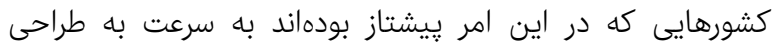

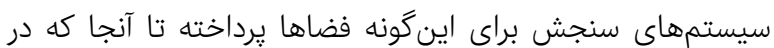
بسيارى از نقاط جهان ابزارهاى ارزيابى متعددى براى سنجش برى 


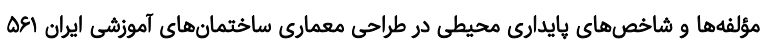

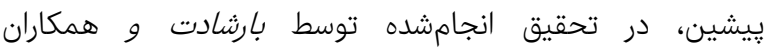

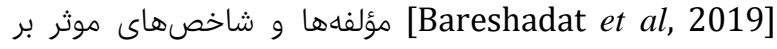
קايدارى محيطى مدارس ايران با تأكيد بر دو سيستم LEED و

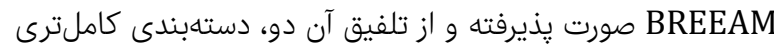

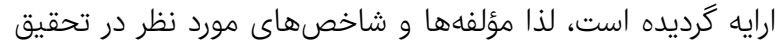

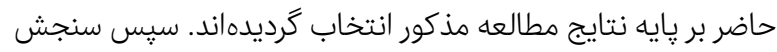

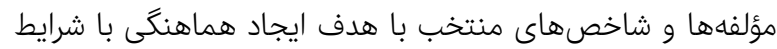

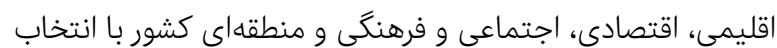

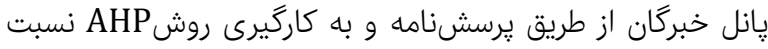

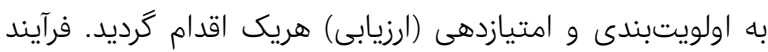
انجام تحقيق در نمودار ا آمده است.

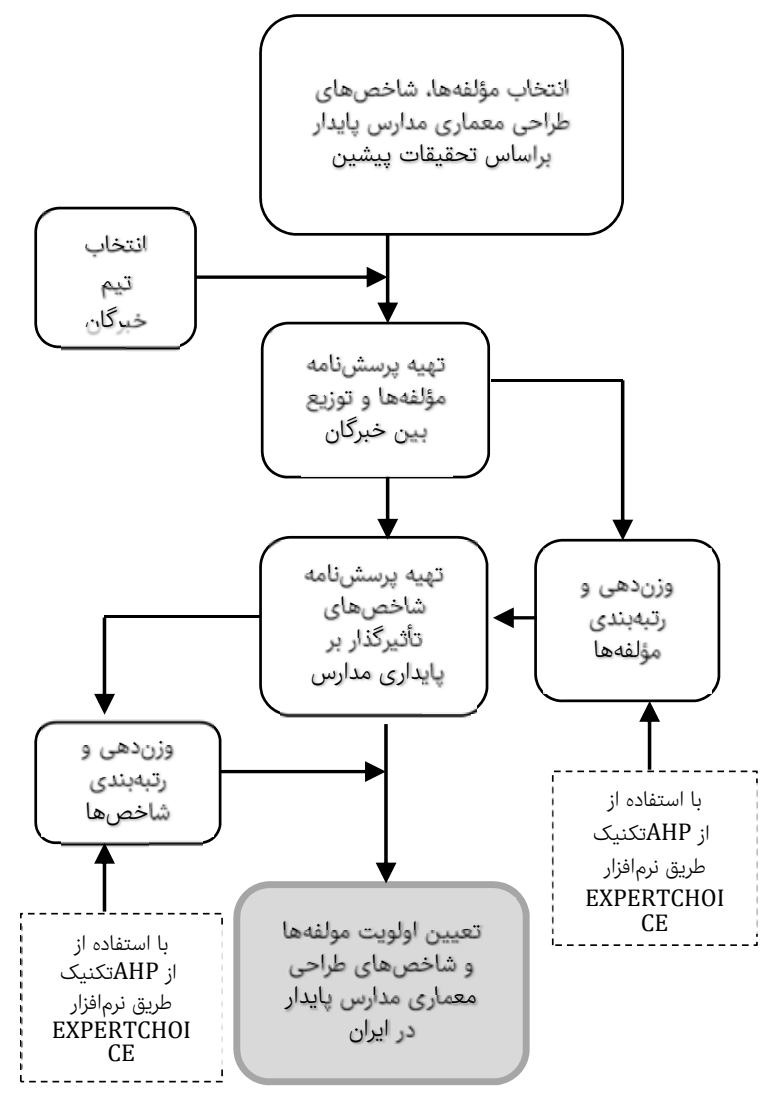

نمودار () فرآيند انجام تحقيق

بدين منظور يس از ترسيم درخت سلسله مراتبى، ״رسشنامه

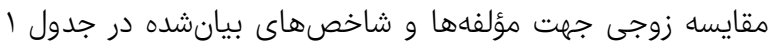

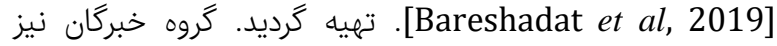

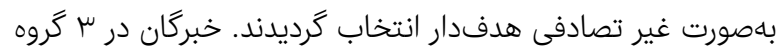

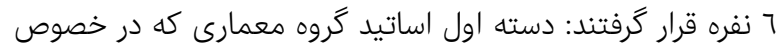

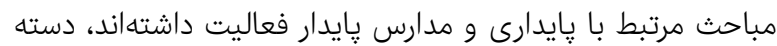
دوم: اساتيد گروه محيطزيست و يا رشتههاى وابسته كه در مرائ مورد

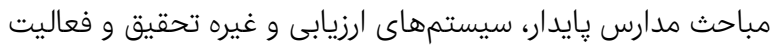

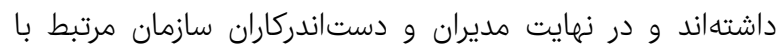
ساختوساز مدارس و يا محيطزيست. در نهايت پاسخهاى به دست مرست

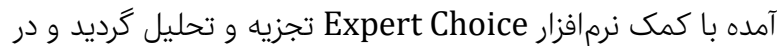

قابل ذكر است كه بيشتر توجه محقق در اين يُزوهش بر جنبههاى

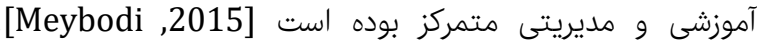

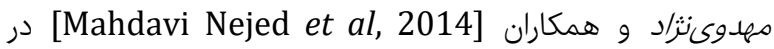
تحقيق خود با هدف تجزيه و تحليل يروزههاى كنونى معمارى يايدار

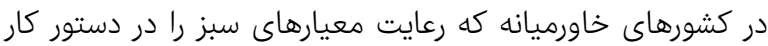
قرار دادهاند، به اين نتيجه رسيدند كه معيارهاى ارايهشده ابزارى كارا

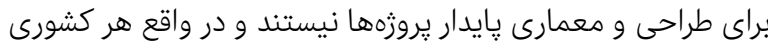

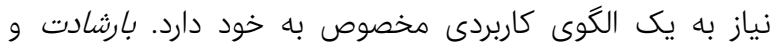

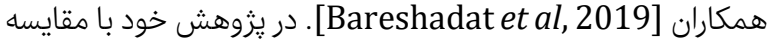
نتايج تحقيقات كذشته جهار سيستم BREEAM،LEED، CASBEE فضاهاى آموزشى سبز شناسايى و با مقايسه آنها براساس جهار

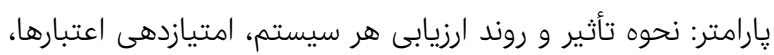
حداقل امتياز به دست آمده و دستابندى معيارها، دو سيستم

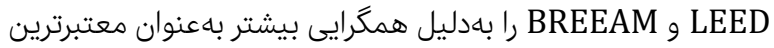
سيستمهاى ارزيابى بينالمللى معرفى نمودهاند. تحقيقى نيز با هدف تبيين دلايل تفاوت روشهاى رتبهابندى مختلف با عنوان "

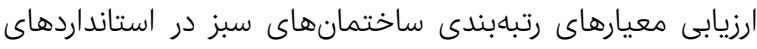

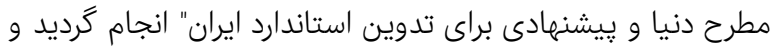

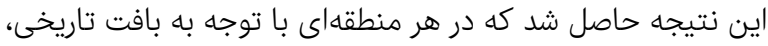

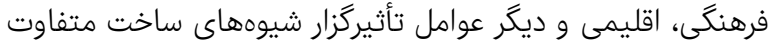
است و انتظار يك سيستم ارزيابى واحد با جزئيات يكسان براى كل جهان واقع گرايانه نيست [Majrohi Sardorood et al, 2012] مطالعه ييشينه يزوهش در خصوص انتخاب سيستمهان فيس ارزيابى يايه حاكى از آن است كه در بررسىهاى انجام شده توسط محققين، از بين سيستمهاى ارزيابى ساختمانهاى سبز آموزشى دو سيستم LEED و از ازعتبار بيشترى برخوردار هستند. ليكن مطالعات انجامشده در ايران در خصوص موضوع تحقيق حاضر، نشان

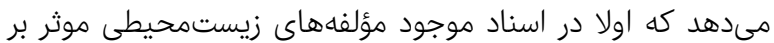

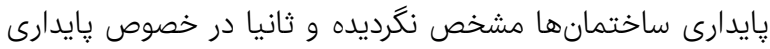

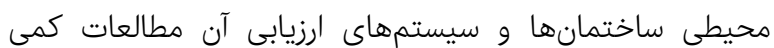
صورت ڤذيرفته است و در آن مطالعات نيز تأكيد بر يك سيست سيستم

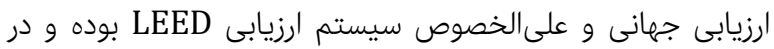

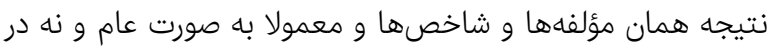

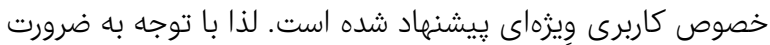

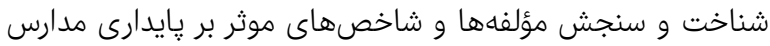

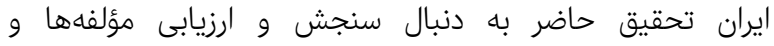

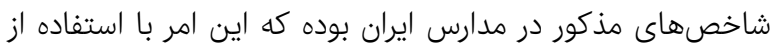
نظرات تيم تخصصى و بكارگيرى تكنيك AHP انجام يذيرفته است.

\section{روش}

با توجه به هدف يزوهش روش تحقيق از نظر هدف كاربردى و از

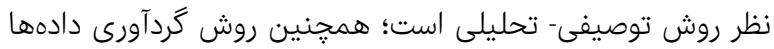

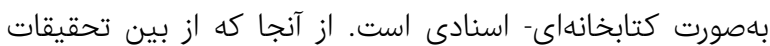


r r اسامى اختصارى عوامل يزوهش جهت استفاده در ماتريسها

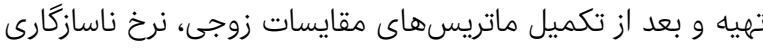

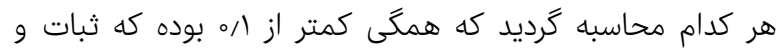

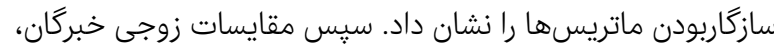

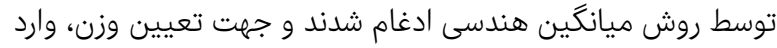

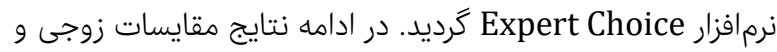

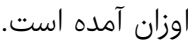

\begin{tabular}{|c|c|c|c|}
\hline & & قى عوامل يزروهش & كول r (r) مـ \\
\hline كد & شاخص & مؤلفه & رديف \\
\hline $\mathrm{E}_{1}$ & بهبود كارايى انرزى & & 1 \\
\hline $\mathrm{E}_{2}$ & استراتثى كاهش CO2 & & r \\
\hline $\mathrm{E}_{3}$ & محيط استفاده از انرثىهاى تجديديذير & 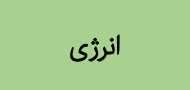 & $\mu$ \\
\hline $\mathrm{E}_{4}$ & اجتناب از نفوذ هوا هبوارجه ساختمان و & & k \\
\hline $\mathrm{W}_{1}$ & كاهش مصرف آب & & $\Delta$ \\
\hline & محوطه كارى و آبيارى مصرف آب براى & 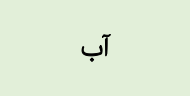 & $\varepsilon$ \\
\hline $\mathrm{W}_{3}$ & بازيافت آب & & $\checkmark$ \\
\hline $\mathrm{S}_{1}$ & مشخصات سايت & & $\wedge$ \\
\hline $\mathrm{S}_{2}$ & تراكم ساختمانها و همجوارى در & سايت & 9 \\
\hline $\mathrm{S}_{3}$ & كاهش اثرات جزاير حرارتى & & 10 \\
\hline $\mathrm{S}_{4}$ & طراحى آبراه هـا & & 11 \\
\hline $\mathrm{I}_{1}$ & دستيابى كافى به نور طبيعى & كيفيت محيط & ir \\
\hline $\mathrm{I}_{2}$ & ايجاد جشم انداز & داخلى & سו \\
\hline $\mathrm{I}_{3}$ & بهبود عملكرد سطح روشنايى & & If \\
\hline $\mathrm{I}_{4}$ & تهويه طبيعى & & 10 \\
\hline $\mathrm{I}_{5}$ & و آلاينده استفاده از تركيبات آلى فرار & & 18 \\
\hline $\mathrm{I}_{6}$ & كاهش آلودگى صوتى & كيفيت محيط & iV \\
\hline $\mathrm{I}_{7}$ & كاهش آلودگى هاى نورى & داخلى & 11 \\
\hline $\mathrm{I}_{8}$ & بهبود عملكرد آكوستيكى & & 19 \\
\hline $\mathrm{I}_{9}$ & 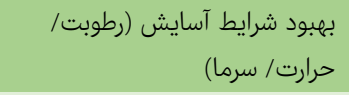 & & $r_{0}$ \\
\hline $\mathrm{M}_{1}$ & محلى و بوم آورد استفاده از مصالح و محصولات & & r) \\
\hline $\mathrm{M}_{2}$ & مصالح تجديديذير & & rr \\
\hline $\mathrm{M}_{3}$ & استفاده از مواد قابل بازيافت & & $r \mu$ \\
\hline $\mathrm{M}_{4}$ & به كاركيرى مقاوم مصالح با اثرات & مواد و مصالح & $\mu k$ \\
\hline $\mathrm{M}_{5}$ & زيست محيطى كم در داخل & & ro \\
\hline $\mathrm{M}_{6}$ & زيست كحيطي عاريق كمر حرارتى با اثرات & & re \\
\hline- & - & اولويت منطقهاى & rV \\
\hline- & - & نوآورى در طراحى & ru \\
\hline
\end{tabular}

اين مدل مشخصكننده رابطه زوجى بين مؤلفهها و شاخصها بوده
نهايت ميزان اهميت هر يك از مؤلفهها و شاران شاخصهاى مدارس يايدار در ايران استخراج گَرديد.

جدول () مؤلفهها و شاخصهاى طراحى معمارى مدارس پايدار Barshadat]

\begin{tabular}{|c|c|}
\hline شاخص & مولفه \\
\hline دستيابى كافى به نور & $\bullet$ \\
\hline ايجاد جشم/نداز & $\bullet$ \\
\hline بهبود عملكرد سطوح روشنايى & $\bullet$ \\
\hline تهويه طبيعى ت & - \\
\hline عدم استفاده از تركيبات آلى فرار و آلاينده & \\
\hline كاهش آلودگى صوتى & $\bullet$ \\
\hline كاهش آلودگىهاى نورى & $\bullet$ \\
\hline بهبود عملكرد آكوستيكى & $\bullet$ \\
\hline بهبود شرايط آسايش (رطوبت/ حرارت/ سرما) & $\bullet$ \\
\hline مشخصات سايت & $\bullet$ \\
\hline \multicolumn{2}{|l|}{ تراكم ساختمانها و همجوارى در محوطه و } \\
\hline \multicolumn{2}{|c|}{ طراحى سايت هكونكى ارتباط آنها } \\
\hline كاهش اثرات جزاير حرارتى & $\bullet$ \\
\hline طراحى آبراه ها & $\bullet$ \\
\hline \multicolumn{2}{|l|}{ استفاده از مصالح و محصولات محلى و بومآورد } \\
\hline استفاده از مصالح تجديديذير & $\bullet$ \\
\hline استفاده از مواد قابل بازيافت & $\bullet$ \\
\hline طراحى مقاوم & - مواد و مصالح \\
\hline \multicolumn{2}{|c|}{ 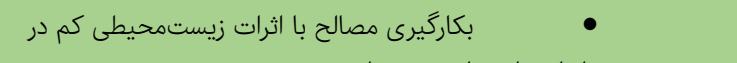 } \\
\hline \multicolumn{2}{|c|}{ 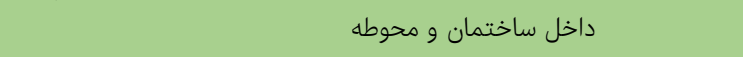 } \\
\hline \multicolumn{2}{|c|}{ 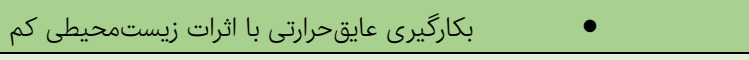 } \\
\hline \multirow{3}{*}{ كاهش مصرف آب كرف كرد مصب براى محوطهكارى و } & $\bullet$ \\
\hline & $\bullet$ \\
\hline & 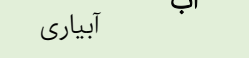 \\
\hline بازيافت آب & $\bullet$ \\
\hline \multirow{5}{*}{ 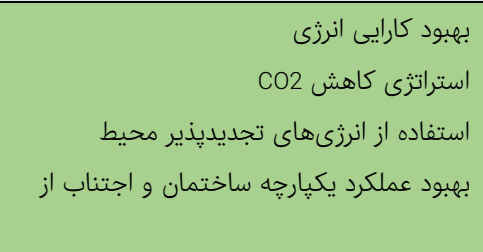 } & $\bullet$ \\
\hline & $\bullet$ \\
\hline & انرثى \\
\hline & $\bullet$ \\
\hline & نفوذ هوا \\
\hline خلاقيت و نوآورى & 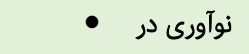 \\
\hline اولويتهاى منطقهاى & 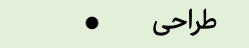 \\
\hline
\end{tabular}

\section{يافتهها}

بهمنظور تطبيق مؤلفهها و شاخصهاى به دست آمده با شرايط كشور و تعيين اولويت هريك، از فرآيند تحليل سلسله مراتبى استفادهاه

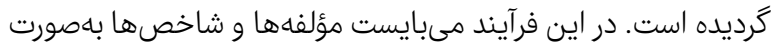

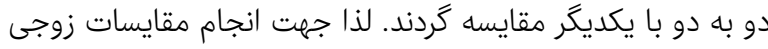
مؤلفهها و شاخصها، ابتدا ترسيم مدل تحليل سلسله مراتبى صورت

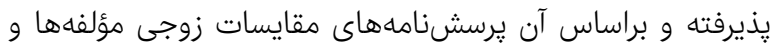

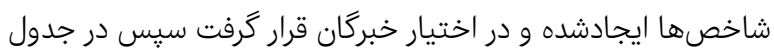




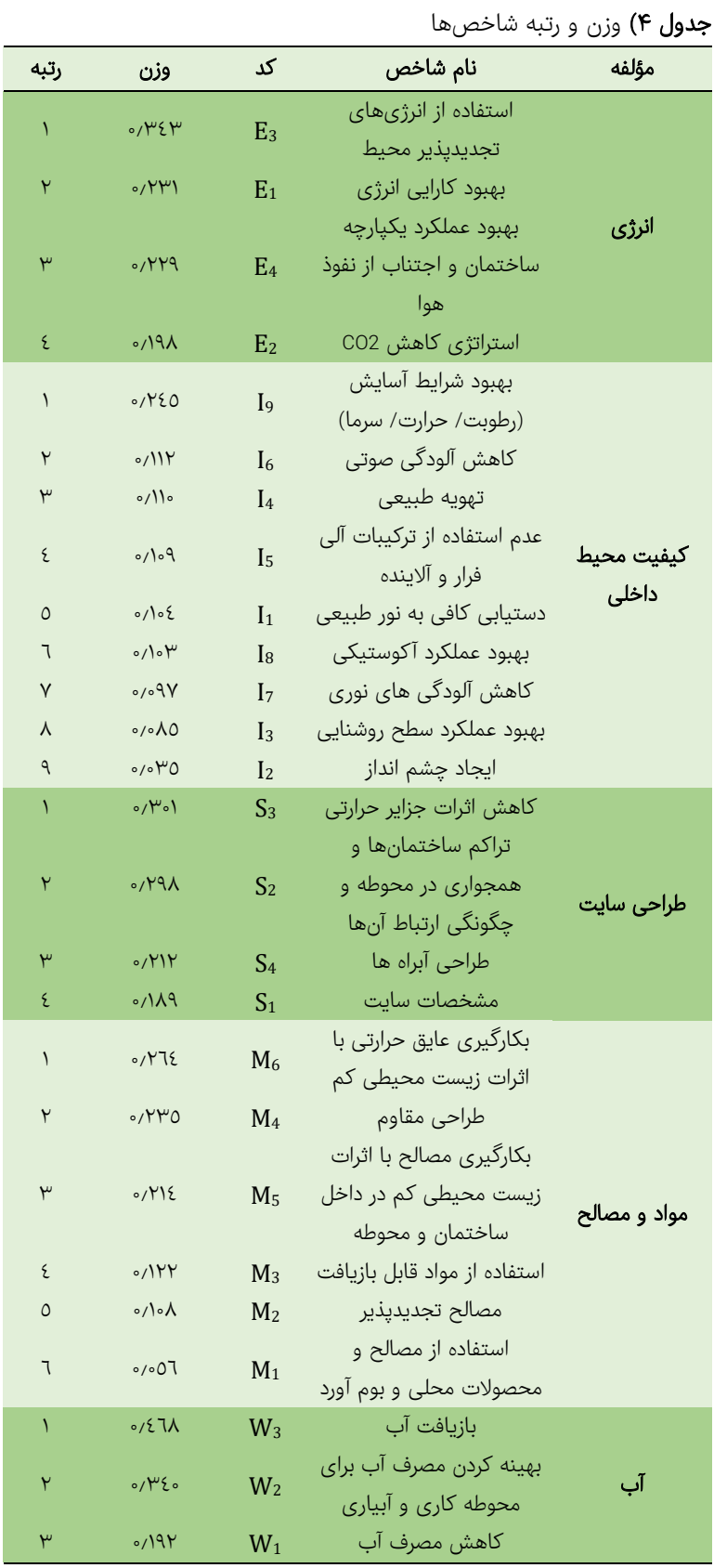

و از سه رديف، هدف، مؤلفهها و شاخصها تشكيل شده است.

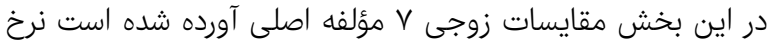

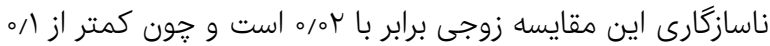
است نشان از سازگارى قابل قبول است.

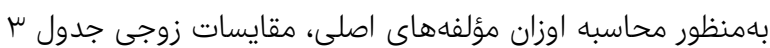

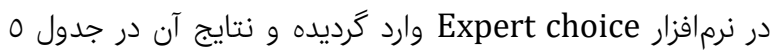
آورده شده است.

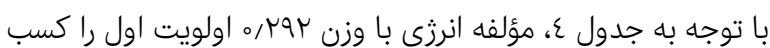

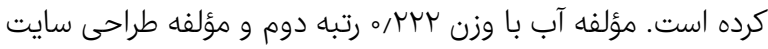
با وزن البره رتبه سوم را كسب كرده است. سيس به طريق مشابه، مقايسه زوجى شاخصهاى هر مؤلفه

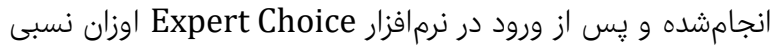
محاسبه گرديده است. يس از تعيين اولويت هريك از شاخصها، در نهايت وزن نهايده نهايى

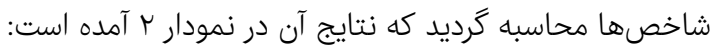

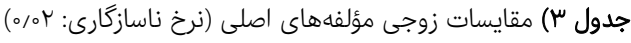

\begin{tabular}{|c|c|c|c|c|c|}
\hline 7 & $\varepsilon$ & $\mu$ & r & 1 & شاخص \\
\hline & & & & & ا- انرثىى \\
\hline & & & 1 & $\mu / \circ \wedge \Lambda$ & r- اب \\
\hline & & 1 & 1,ror & $1,7 \pi 9$ & س- طراحى سايت \\
\hline & 1 & $0 / 0 \varepsilon V$ & remar & $r / 001$ & ع- كيفيت محيط داخلى \\
\hline 1 & 1,491 & $r / 007$ & w/quo & w/V & 0- مواد و مصالح \\
\hline l/AMA & r/OHT & $\mu / v \vee \mu$ & $\varepsilon / \varepsilon \varepsilon V$ & $\varepsilon / 0 \varepsilon \varepsilon$ & 7- اولويت منطقهاى \\
\hline $1, \pi 7 \lambda$ & H/हro & $\varepsilon / \vee \mu$ & $\varepsilon / \wedge \mid \mu$ & r/001 & V- نوآورى در طراحى \\
\hline
\end{tabular}

\begin{tabular}{|c|c|c|}
\hline رتبه & وزن & تام مؤلفه مؤلفهاى اصلى \\
\hline 1 & - rar & انرثى \\
\hline r & ORYK & آب آ \\
\hline$\mu$ & $0, M 10$ & طراحى سايت \\
\hline$\varepsilon$ & $\% 999$ & كيفيت محيط داخلى \\
\hline 0 & $\% \circ \gamma \mu$ & مواد و مصالح \\
\hline 7 & $\% 00 \varepsilon$ & اولويت منطقهاى \\
\hline v & $\% \varepsilon 0$ & نوآورى در طراحى \\
\hline
\end{tabular}

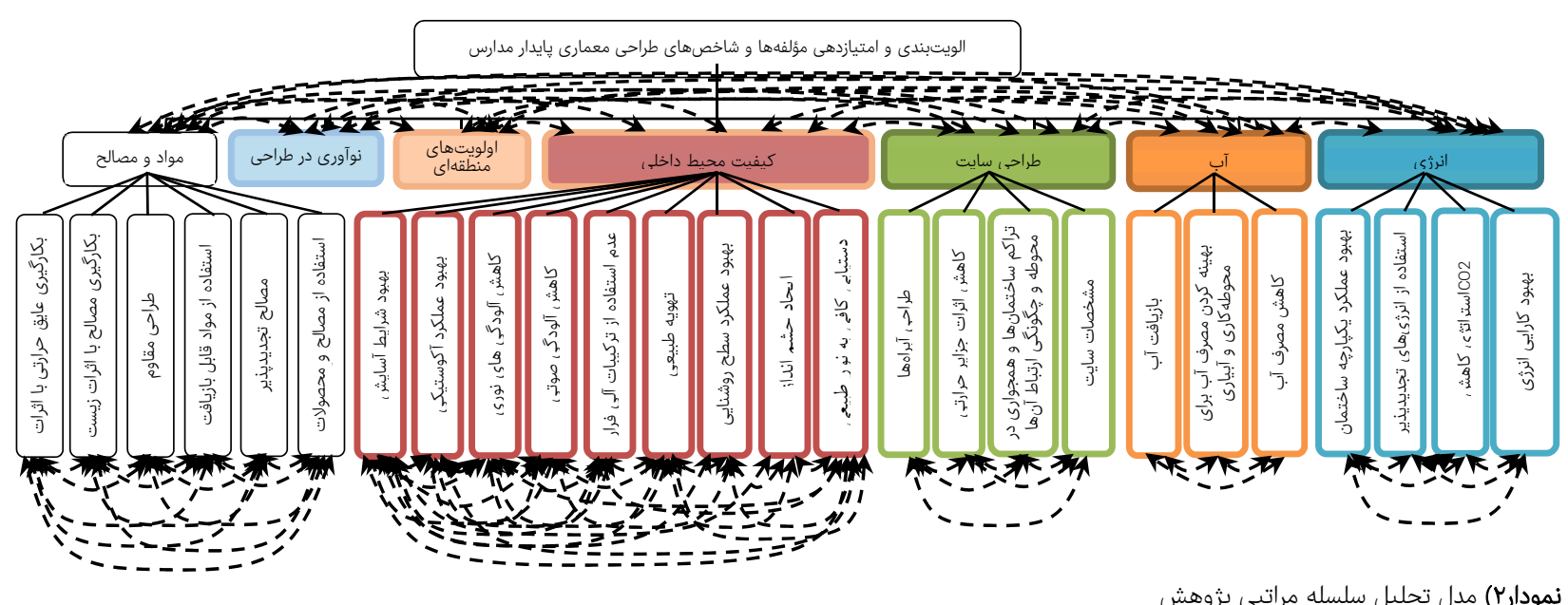

نمودارץ) مدل تحليل سلسله مراتبى يزوهش 
يديده جزاير حرارتى مواجه هستيم. از دلايل اين امر مىتوان به

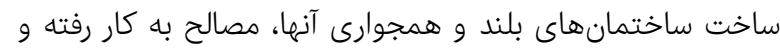

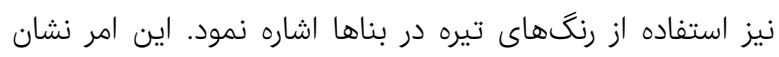

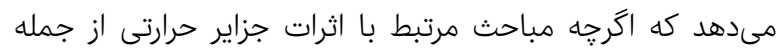

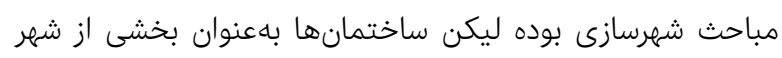
نقش تأثيرگذارى را بازى ايفا مىنمايند. بوده ليكن ساختمان. مقايسه شاخصهاى كيفيت محيط داخلى با يكديگر و نيز اوزان به

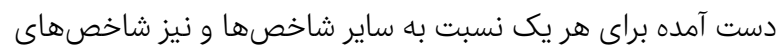

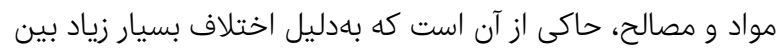

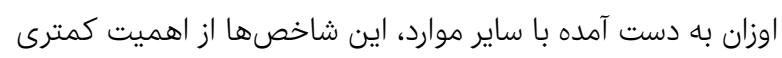

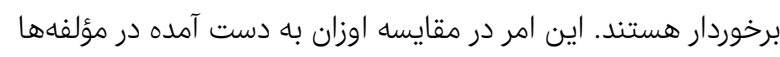

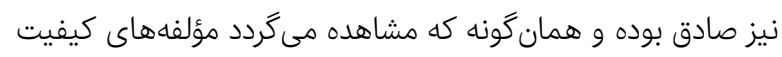

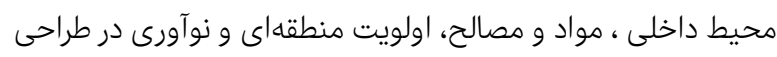

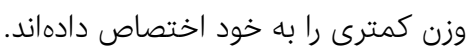

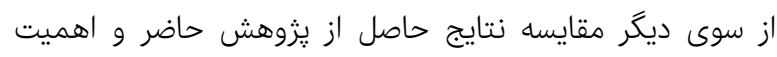

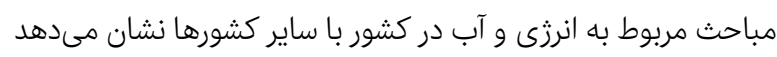

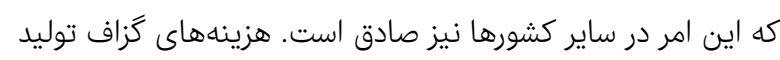

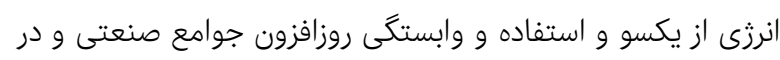

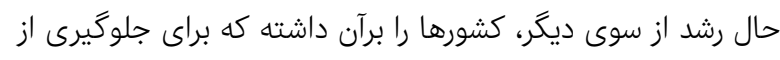

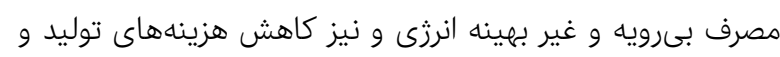

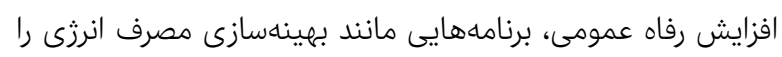

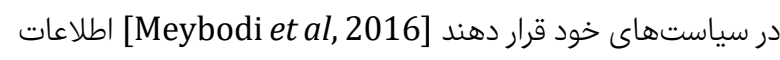
سازمان ملل نيز تأكيدى است بر اين امر، جرا كراس كه براساس اطلاعات إنهات

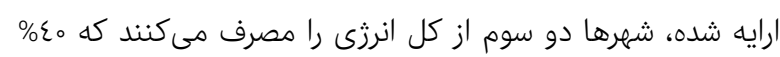

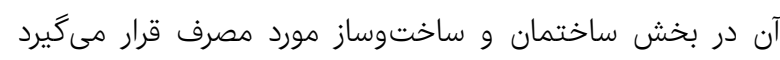

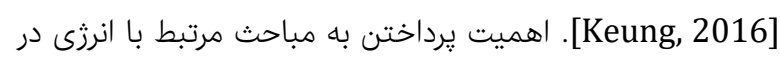
سيستمهاى ارزيابى ازجمله LEED و

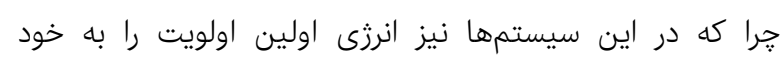
اختصاص دهد [LEED, 2016]. بنابراين ارايه راهكارهايى در جهت إنه كاهش مصرف انرزى و صرفهجويى در مصرف آب در فضاهاى

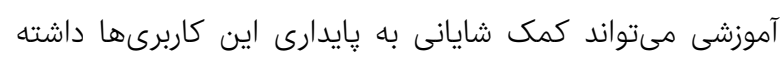

\section{نتيجه}

مقايسات انجامشده در تحقيق حاضر با هدف تعيين اولويت

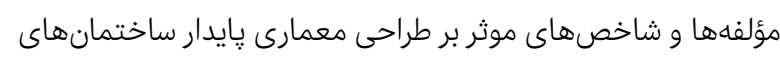

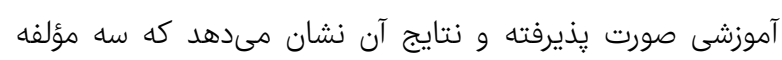

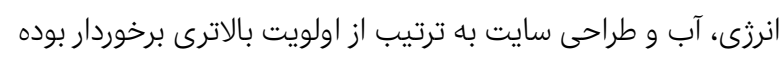

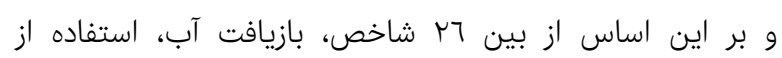

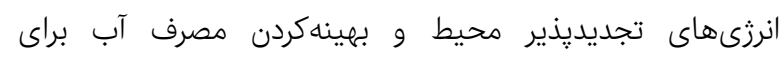

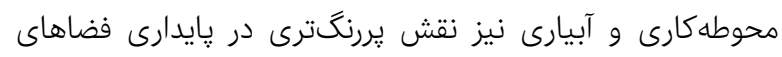

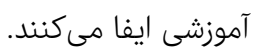
تشكر و قدردانى: موردى توسط نويسندگًان گزارش نشده است.
در نتايج حاصل از مقايسه زوجى مؤلفهها، تفاوت بسيارى بين

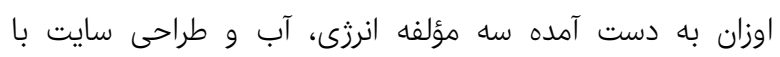

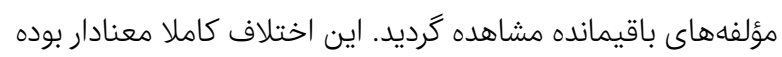

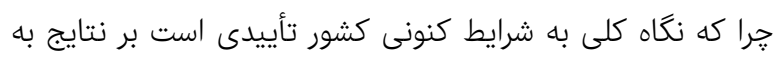

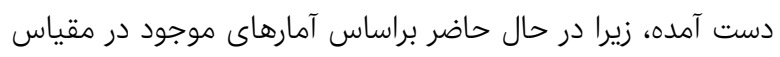

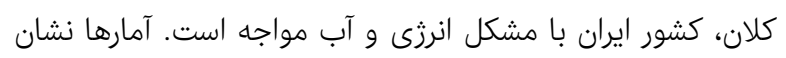

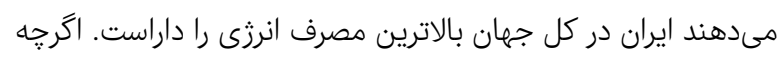
يك درصد جمعيت جهان را ايرانيان تشكيل مىدهند لئن ليكن دو درصد

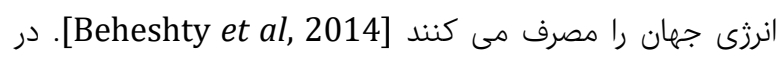
زمينه آب نيز براساس شاخص سازمان ملل كشور ايران با ضريب مان

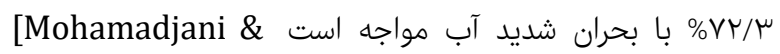
.Yazdanian, 2014] نتايج حاصل از مقايسات زوجى شاخصهاى مربوط به هر مؤلفه

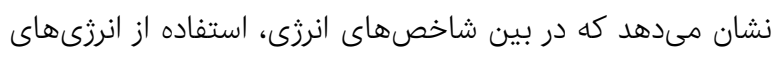

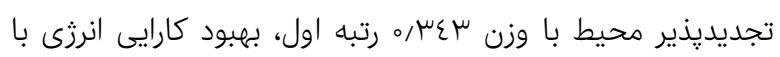

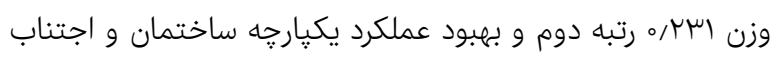
از نفوذ هوا با وزن وبr/ه رتبه سوم را كسب نموده است. مقايسه

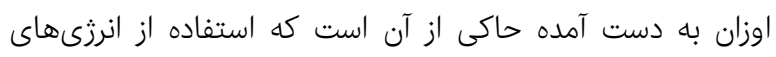

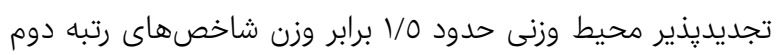

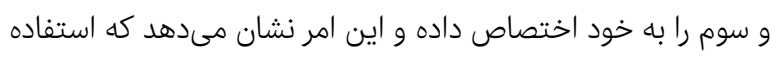

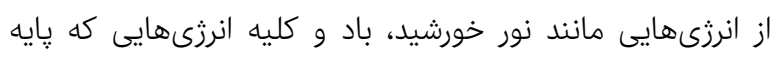

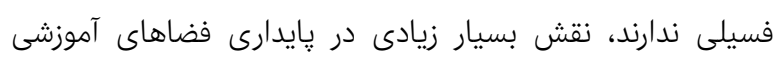

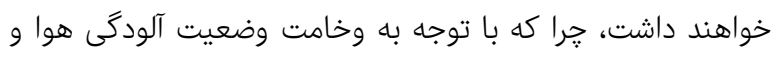

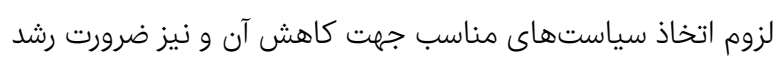

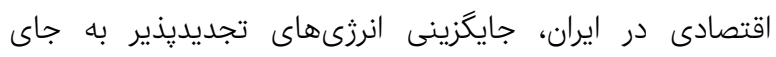

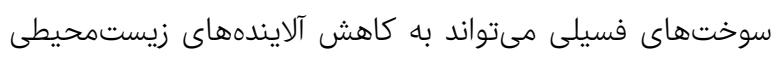

منجر شود [Sadeghi et al, 2017] در اوزان به دست آمده از مقايسه زوجى شاخصهاى آل آب، بازيافت

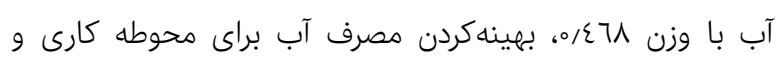

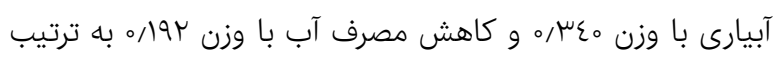
رتبههاى اول تا سوم را كسب نموده است. اختلاف زياد وزياد بين رتبه سوم با شاخصهاى مربوط به رتبه اول و دوم بسيار معنادار بوده

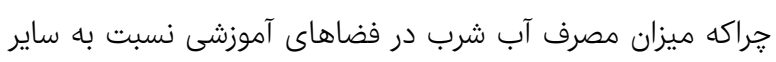

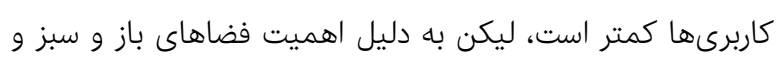

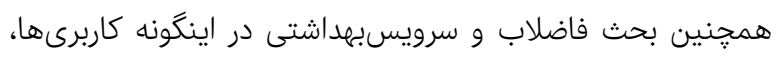

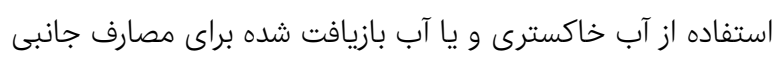
از اهميت زيادى برخوردار است. از بين شاخصهاى طراحى سايت، رتبههاى اول تا سوم به ترتيب

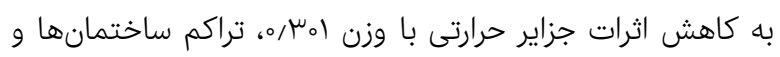

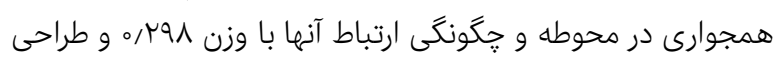

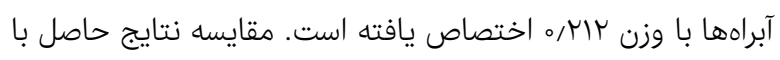

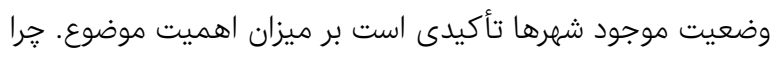

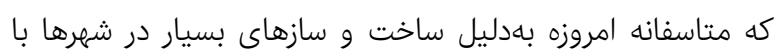


مؤلفهها و شاخصهاى يايدارى محيطى در طراحى معمارى ساختمانهاى آموزشى ايران ه\&D massing. Kaveh N, translator. Tehran: Royal Institute of Architectural Science. [Persian]

LEED 2009 (2016). LEED for schools-new construction v2009. Washington, D.C: Usgbc.

Lee W (2012). Benchmarking energy use of building environmental assessment schemes. Energy and Buildings. 45:326-334.

Mahdavi Nejad M, Zia A, Norouzi Larki A, Ghanavati S, Elmi N (2014). Dilemma of green and pseudo green architecture based on LEED norms in case of developing countries. International Journal of Sustainable Built Environment. 3(2):235-245.

Majrohi Sardorood J, Haji Aqa Bozorgi H, Chehrzad M (2017). Evaluation of green building rating criteria in world standards and proposed standards for Iranian standard formulation. Journal of Civil and Environmental Engineering. 47(4):74-93. [Persian]

Meybodi H (2015). Proposing a model of green schools assessment in Iran using fuzzy multi-criteria decision making methods. [dissertation]. Tehran: Islamic Azad University, Science and Research Branch. [Persian] Meybodi H, Lahijanian A, Sabiri SM, Jozi SA, Azizi Nejad R (2016). Developing standard criteria for geen schools in Iran. Quarterly Journal of Education. 127(32):107-129. [Persian]

Mohamadjani E, Yazdanian N (2014). Analysis of the situation of water crisis in the country and its management requirements. Ravand. 21(65-66):117-144. [Persian]

OECD (2001). The DAC guidelines, strategies for sustainable development. Paris: OECD

Ramli N, Masri M, Zafrullah M, Taib H, Abd Hamid N (2012). A comparative study of green school guidelines. Procedia-Social and Behavioral Sciences. 50:462-471. Sadeghi SS, Sojoodi S, Ahmadzadeh Deljavan F (2017). The impact of renewable energy on economic growth and environmental quality in Iran. Quarterly Journal of Energy Policy and Planning Research. 3(6):171-202. [Persian]

$$
\begin{aligned}
& \text { تأييديههاى اخلاقى: موردى توسط نويسندگًان گزارش نشده است. } \\
& \text { تعارض منافع: موردى توسط نويسندگًان گزارش نشده استان. }
\end{aligned}
$$

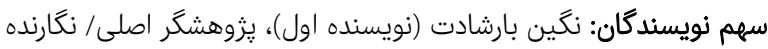

$$
\begin{aligned}
& \text { بحث (0\%)؛؛ حميدرضا شعاعى (نويسنده دوم)، يزوهشگر كمكى/تحليلگر }
\end{aligned}
$$

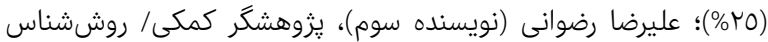

منابع مالى: اين مقاله مستخرج از رساله دكترى نگين بارشادت به راهنمايى اساتيد محترم آقايان دكتر شعاعى و دكتر رضوانى در دانشگاه آزاد اسلامى واحد مشهد است.

Alyami S, Rezgui Y (2012). Sustainable building assessment tool development approach. Sustainable Cities and Society. 5:52-62.

Bahreini H, Maknoon R (2001). Sustainable urban development from thought to Action. Journal of Environmental Studies. 27(27):41-60. [Persian]

Bareshadat N, Shoaei HR, Rezvani A (2019). Explaining the components and Indices of environmental sustainability in Iran's educational spaces, with an emphasis on green educational building evaluation systems. Journal of Environmental Studies. 45(1):171192. [Persian]

Beheshty SS, Ghasemi V, Ghazi Tabatabaei M, Rafatjah M (2014). A sociological study of the impact of attitudes on energy consumption. Iranian Electric Industry Journal of Quality and Productivity. 3(6):3-10. [Persian]

Bernardi E, Carlucci S, Cornaro C, Bohne R (2017). An analysis of the most adopted rating systems for assessing the environmental impact of buildings. Sustainability. 9(7).

Keung J (2016). Green building- building planning and 